\title{
Esophago gastro duodenos copy helpful to avoid unnecessary cholecystectomy
}

\author{
Dr.P.Sabitha ${ }^{1}$ Dr. Md.Ghouse ${ }^{2}$ Dr.S.Nagamuneiah ${ }^{3}$ \\ ${ }^{1}$ Assistant Professor of Surgery, SV Medical College, Tirupati \\ ${ }^{2}$ Postgraduate In General Surgery, SV Medical College, Tirupati \\ ${ }^{3}$ Associate Professor of Surgery, SV Medical College, Tirupati
}

\begin{abstract}
: gallstone disease is one of the most prevalent diseases in man with age,gender, ethnicity and life style playing important roles in gallstone formation. mostly gallstones are asymptomatic. upper GI symptoms may simulate symptoms of gall stone disease, resulting in cholecystectomy. esophago gastro duodenoscopy prior to surgery may identify these problems and can help to avoid unnecessary chlecystectomy and persistent post operative symptoms.
\end{abstract}

\section{Introduction}

Gall stone disease is one of the most prevalent diseases in man with age, gender, ethnicity and lifestyle playing important roles in the formation of gall stones. Incidence of asymptomatic gallstones has been understood recently, largely due to application of USG scanning of people for other reasons. Most of the gall stones are silent / asymptomatic with only $1-4 \%$ lifetime risk of becoming symptomatic. Cholelithiasis can present with a complex combination of clinical symptoms which may resemble the presentation of other gastrointestinal diseases. Hence, the use of routine preoperative investigations like upper gastrointestinal endoscopy prior to planning surgical treatment of cholelithiasis may help to identify other potentially treatable medical conditions and hence may reduce overall cholecystectomy rates. Besides its cost effectiveness, it may potentially help in reducing the incidence of postoperative persistence of symptoms.

\section{Aim And Objective}

To identify the various common upper gastrointestinal lesions seen on upper gastrointestinal endoscopy in gall stone disease patients.

\section{Materials And Methods}

3.1 Source Of Data- Forty patients attending OPD/admitted to department of surgery in SVRRGGH, Tirupati were considered for the study.

\subsection{Method Of Collection Of Data}

Patients with USG proved gall-stones presenting with dyspepsia attending OPD or admitted in surgery department were taken for the study. Details of cases were recorded including history and clinical examination and investigations as per the pretested proforma. Upper GI endoscopy was performed to look for significant lesions.

3.3 Sampling- Patients fulfilling the inclusion and exclusion criteria are taken up for the study. Findings are analyzed using graphs.

\subsection{Inclusion Criteria}

1. Patients aged $>18$ years.

2. Patients who have either single or multiple stones in gallbladder as shown in ultrasound abdomen.

3. patients who are willing to participate in the study and have given written informed consent.

\subsection{Exclusion Criteria}

1. Patients with complicated gallstone disease: choledocholithiasis, obstructive jaundice, cholangitis, gallstone pancreatitis, cholecystoenteric fistula, gallbladder neoplasm, previous biliary/pancreatic surgery, previous gastric surgery.

\section{AGE distribution of cases}




\begin{tabular}{|l|l|l|}
\hline Age in years & No. of cases & percentage \\
\hline$<30$ years & 4 & 10 \\
\hline $30-60$ & 33 & 82.5 \\
\hline$>60$ & 3 & 7.5 \\
\hline total & 40 & 100 \\
\hline
\end{tabular}

Table no.1

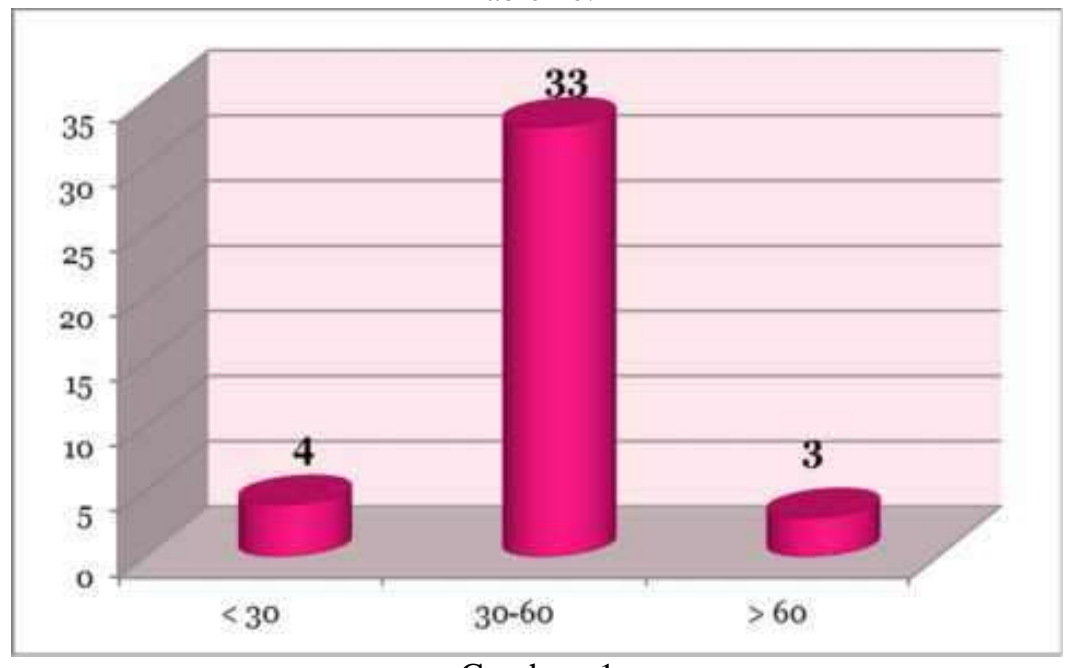

Graph no.1

In the present study, the most common age group presenting with cholelithiasis and dyspepsia was between 30 to 60 years, accounting for $82.5 \%$ followed by less than 30 years age group with $10 \%$.

\section{Sex Distribution}

\begin{tabular}{|l|l|l|}
\hline Sex & No. of cases & Percentage \\
\hline Male & 13 & 32.5 \\
\hline female & 27 & 67.5 \\
\hline total & 40 & 100 \\
\hline
\end{tabular}

Table 2

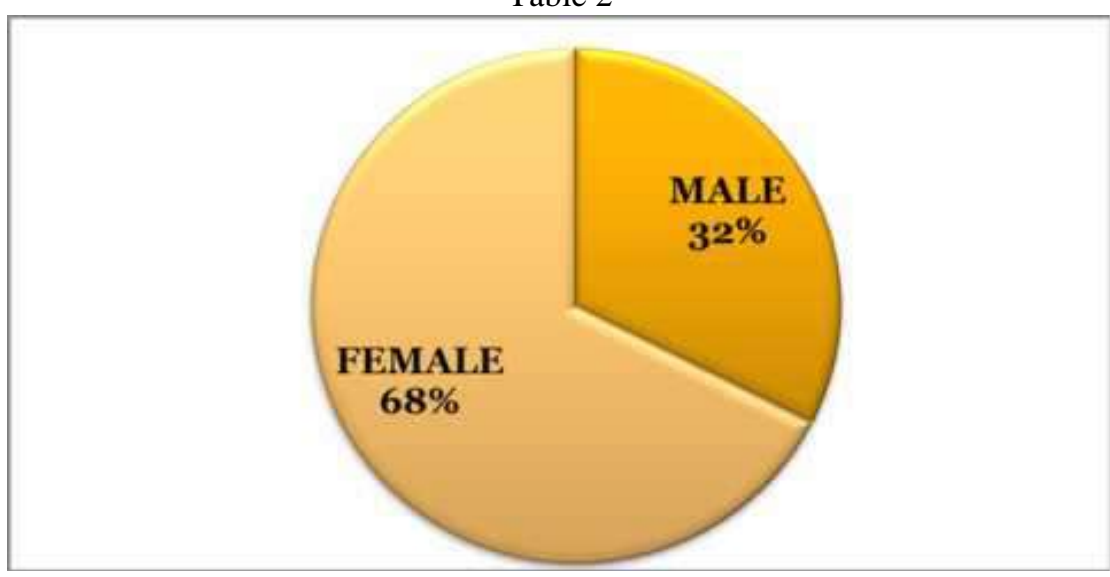

Graph 2

In the present study, cholelithiasis with dyspepsia was more common in females accounting for $67.5 \%$ of the study group.

\section{Dyspeptic Symptoms}

\begin{tabular}{|l|l|l|}
\hline Symptoms & No.of cases & Percentage \\
\hline Pain abdomen & 28 & 70 \\
\hline Heart burn & 19 & 47.5 \\
\hline Belching & 12 & 30 \\
\hline Post prandial fullness & 19 & 47.5 \\
\hline Nausea & 14 & 35 \\
\hline Vomiting & 7 & 17.5 \\
\hline
\end{tabular}


Table 3

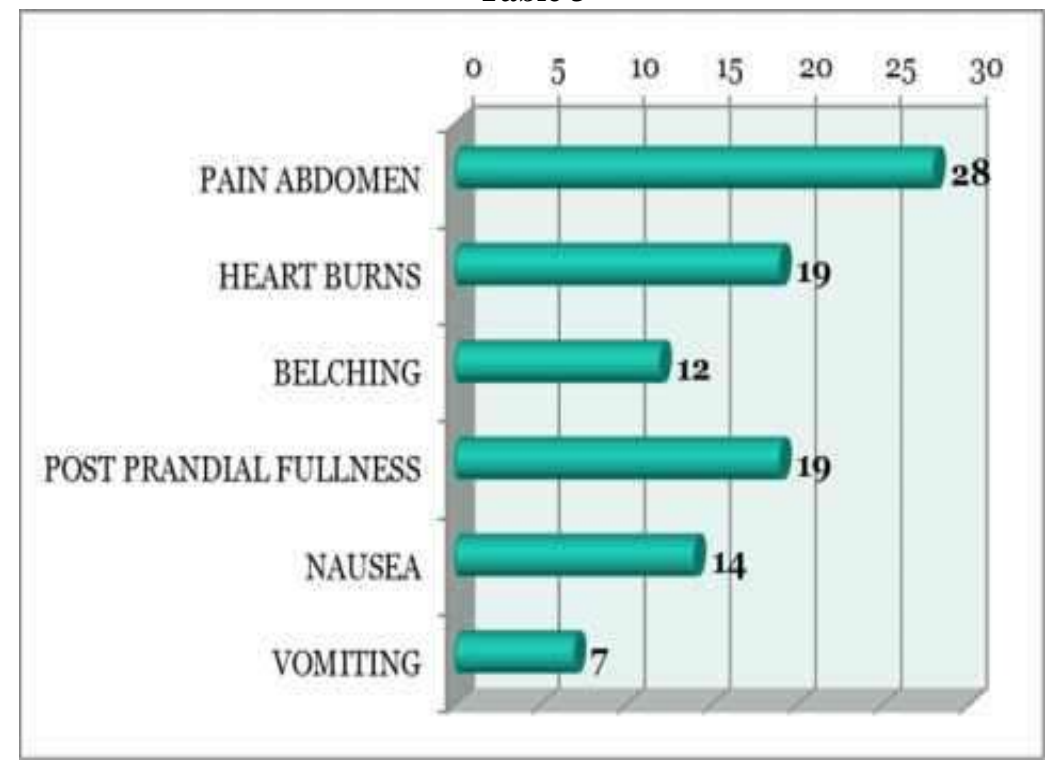

Graph no. 3

In the present study, pain abdomen was the most common dyspeptic symptom seen in 28 cases (70\%),followed by heart burn seen in19 cases $(47.5 \%)$ and post prandial fullness seen in 19 cases (47.5).Other symptoms include nausea (14cases,35\%), belching (12 cases,30\%) and vomiting ( 7 cases, $17.5 \%)$.

VI. Symptom Complex

\begin{tabular}{|c|c|c|}
\hline Symptom complex & $\begin{array}{l}\text { No.of } \\
\text { cases }\end{array}$ & Percentage \\
\hline Pain abdomen+heart burn & 11 & 27.5 \\
\hline Pain abdomen+post prandial fullness & 15 & 37.5 \\
\hline Pain abdomen + Post prandial fullness + nausea & 3 & 7.5 \\
\hline Pain abdomen + Nausea & 10 & 25 \\
\hline Pain abdomen + Heart burns + Post prandial fullness + Nausea & 1 & 2.5 \\
\hline Pain abdomen + Heart burn + Belching + Post prandial fullness & 1 & 2.5 \\
\hline Pain abdomen + Belching + Post prandial fullness & 4 & 10 \\
\hline $\begin{array}{l}\text { Pain abdomen }+ \text { Heart burn }+ \text { Belching }+ \text { Post prandial fullness }+ \\
\text { Nausea }+ \text { Vomiting }\end{array}$ & 1 & 2.5 \\
\hline Heart burn + Belching + Nausea & 1 & 2.5 \\
\hline Post prandial fullness & 19 & 47.5 \\
\hline Post prandial fullness + Nausea & 3 & 7.5 \\
\hline Pain+ Heart burn+ Nausea & 3 & 7.5 \\
\hline Pain + Heart burn + Vomiting & 4 & 10 \\
\hline Belching + Post prandial fullness & 5 & 12.5 \\
\hline Belching+ Post prandial fullness + Nausea & 1 & 2.5 \\
\hline Heart burn + Belching + Post prandial fullness & 2 & 5 \\
\hline Heart burn + Belching + Post prandial fullness + Nausea & 1 & 2.5 \\
\hline Heart burn + Belching + Post prandial fullness + Nausea + & 1 & 2.5 \\
\hline
\end{tabular}




\begin{tabular}{|l|l|l|}
\hline Vomiting & & \\
\hline Heart burn + Nausea & 7 & 17.5 \\
\hline Heart burn + Post prandial fullness & 8 & 20 \\
\hline Heart burn + Post prandial fullness + Nausea & 1 & 2.5 \\
\hline Pain + Belching & 8 & 20 \\
\hline Pain + Belching + Nausea & 3 & 7.5 \\
\hline Pain + Belching + Post prandial fullness + Nausea & 1 & 12.5 \\
\hline Pain + Belching + Post prandial fullness + Nausea + Vomiting & 1 & 2.5 \\
\hline Pain + Heart burn + Belching + Nausea & 1 & 2.5 \\
\hline Pain + Heart burn + Belching + Post prandial fullness + Nausea & 1 & 2.5 \\
\hline Pain + Heart burn + Nausea + Vomiting & 1 & 2.5 \\
\hline Pain+ Post prandial fullness + Nausea + Vomiting 1 2.5 & 1 & 2.5 \\
\hline Pain+ post prandial fullness + nausea+vomiting+fever & 0 & 0 \\
\hline
\end{tabular}

Table 4

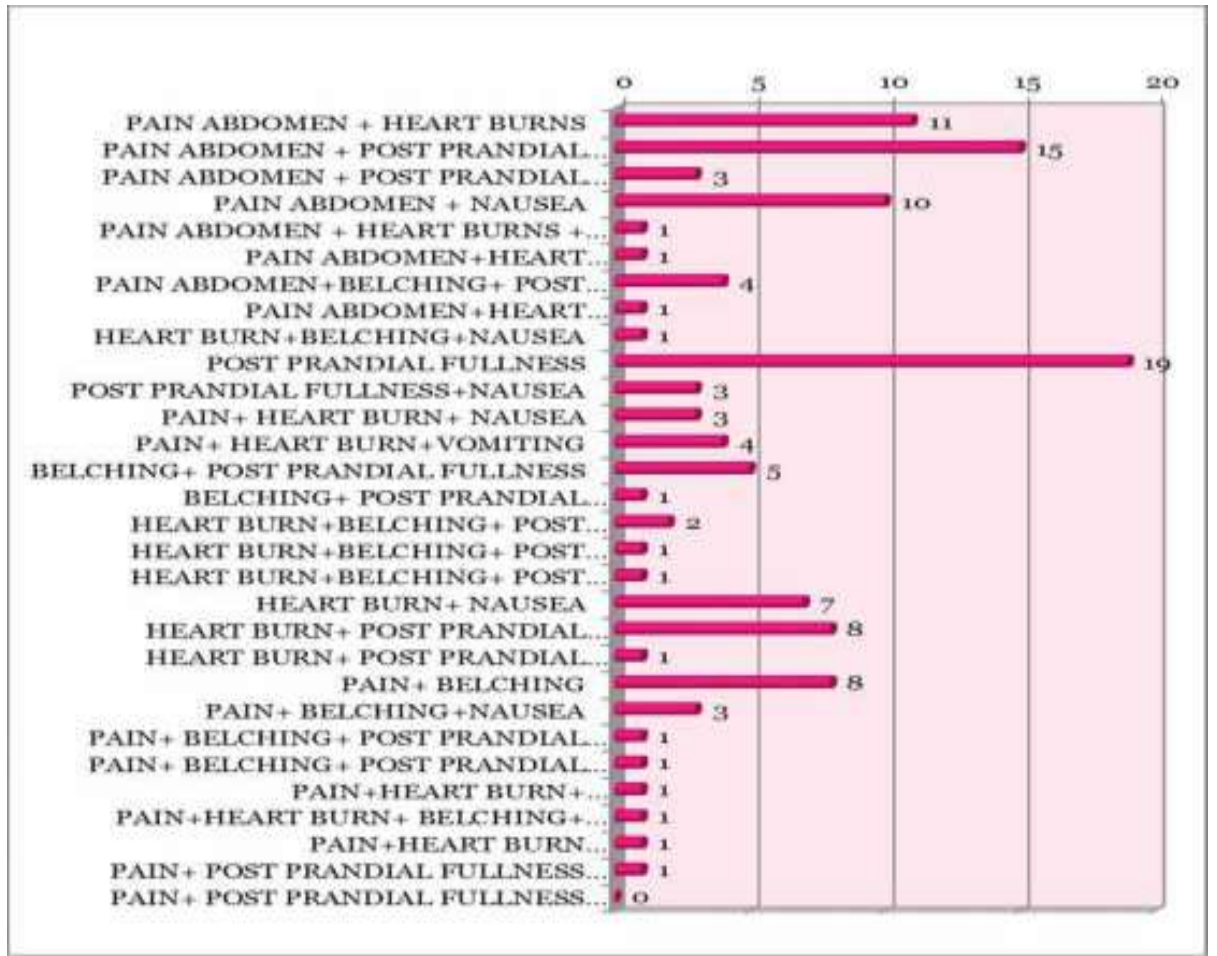

Graph 4

In the present study, pain abdomen + post prandial fullness (37.5) was the most common symptom complex followed by pain abdomen+ heartburn (27.5).

VII. Incidence Of Egd Findings

\begin{tabular}{|l|l|l|}
\hline Incidence & No. of cases & percentage \\
\hline EGD findings & 31 & 77.5 \\
\hline No EGD findings & 9 & 22.5 \\
\hline
\end{tabular}

Table 5 


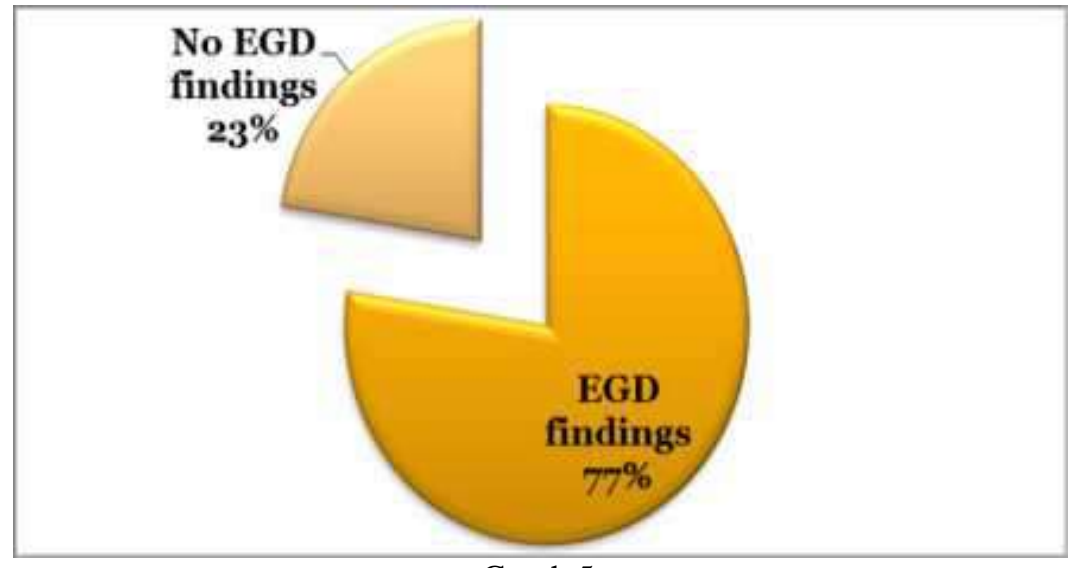

Graph 5

In the present study, out of 40 patients with gallstone disease who were subjected to EGD, 31 patients (77.5\%) had positive upper gastro intestinal findings and 9 patients (22.5\%) had negative EGD.

VIII. Egd Findings

\begin{tabular}{|l|l|l|}
\hline EGD findings & No. of cases & percentage \\
\hline Normal & 9 & 22.5 \\
\hline Esophagitis & 7 & 17.5 \\
\hline Hiatal hernia & 11 & 27.5 \\
\hline Gastritis/gastric ulcer & 17 & 42.5 \\
\hline Duodenitis & 4 & 10 \\
\hline Duodenal ulcer & 4 & 10 \\
\hline
\end{tabular}

Table No.6

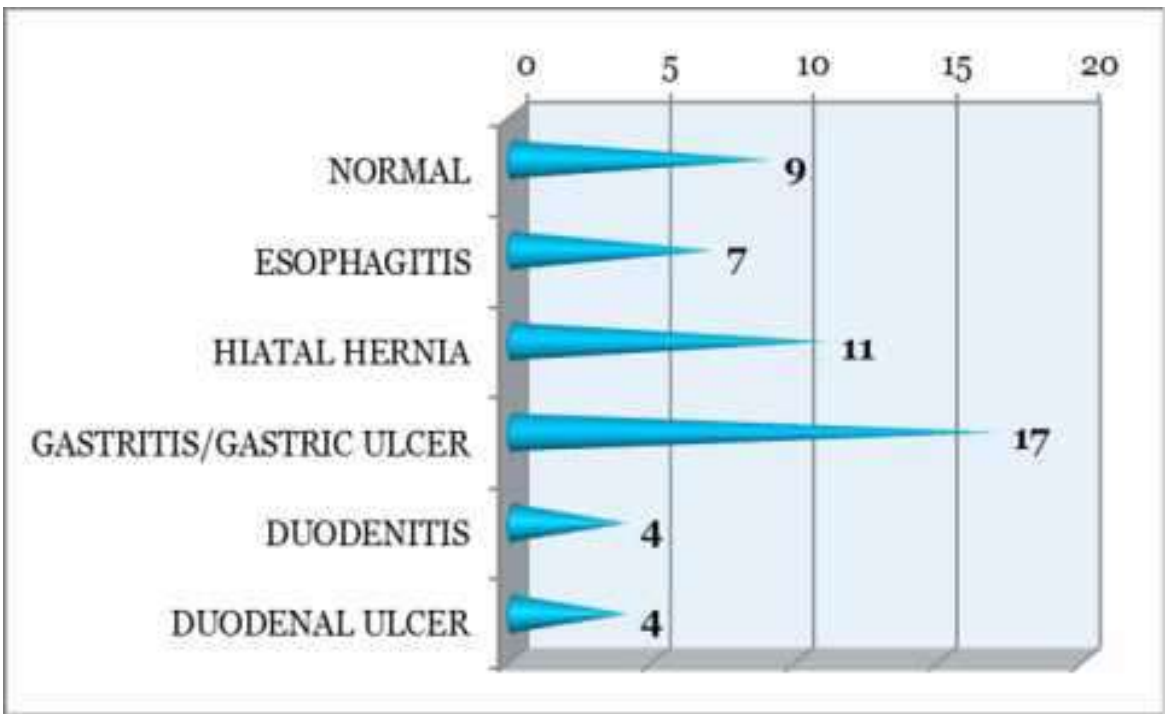

Graph No.6

In the present series, 9 cases $(22.5 \%)$ of the study group had normal study. In patients having significant EGD findings, Gastritis/gastric ulcer (17 cases,42.5\%) accounted for the most common finding, followed by hiatal hernia (11 cases,27.5\%).No EGD related complications were encountered during the study.

10. Egd Finding Combination

\begin{tabular}{|l|l|l|}
\hline EGD findings complex & No of patients & Percentage \\
\hline Normal & 9 & 22.5 \\
\hline Gastritis & 17 & 42.5 \\
\hline Hiatus hernia + Gastritis & 4 & 10 \\
\hline Hiatus hernia & 11 & 27.5 \\
\hline Hiatus hernia + Gastritis + Duodenitis & 0 & 0 \\
\hline Esophagitis + Hiatus hernia & 1 & 2.5 \\
\hline Esophagitis + Hiatus hernia + Gastritis & 1 & 2.5 \\
\hline
\end{tabular}




\begin{tabular}{|l|l|l|}
\hline Gastritis+ Duodenitis & 2 & 5 \\
\hline Duodenitis & 4 & 10 \\
\hline Duodenitis + Duodenal ulcer & 1 & 2.5 \\
\hline Esophagitis & 7 & 17.5 \\
\hline Esophagitis + Gastritis & 4 & 10 \\
\hline $\begin{array}{l}\text { Esophagitis + Gastritis + Duodenitis + } \\
\text { Duodenal ulcer }\end{array}$ & 1 & 2.5 \\
\hline $\begin{array}{l}\text { Esophagitis + Hiatus hernia + Gastritis + } \\
\text { Duodenitis }\end{array}$ & 0 & 0 \\
\hline $\begin{array}{l}\text { Esophagitis + Hiatus hernia + Gastritis + } \\
\text { Duodenitis + } \\
\text { Duodenal ulcer }\end{array}$ & 0 & 0 \\
\hline $\begin{array}{l}\text { Esophagitis + Hiatus hernia + Gastritis + } \\
\text { Duodenal ulcer }\end{array}$ & 0 & 0 \\
\hline $\begin{array}{l}\text { Gastric ulcer + Duodenitis + Duodenal ulcer } \\
12.5\end{array}$ & 1 & 2.5 \\
\hline $\begin{array}{l}\text { Hiatus hernia + Gastritis + Duodenitis + } \\
\text { Duodenal ulcer 0 0 }\end{array}$ & 0 & 0 \\
\hline
\end{tabular}

table no.7

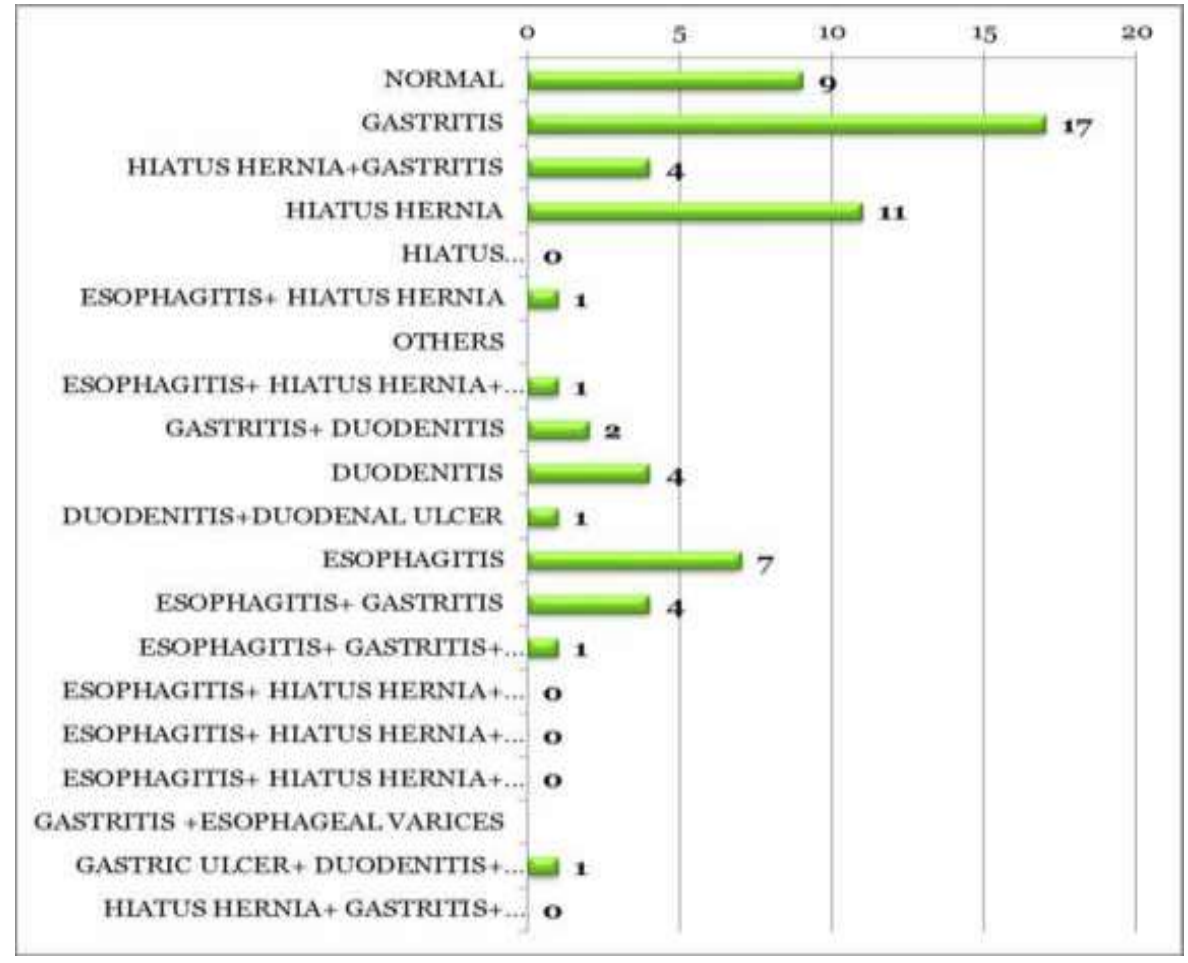

Graph no.7

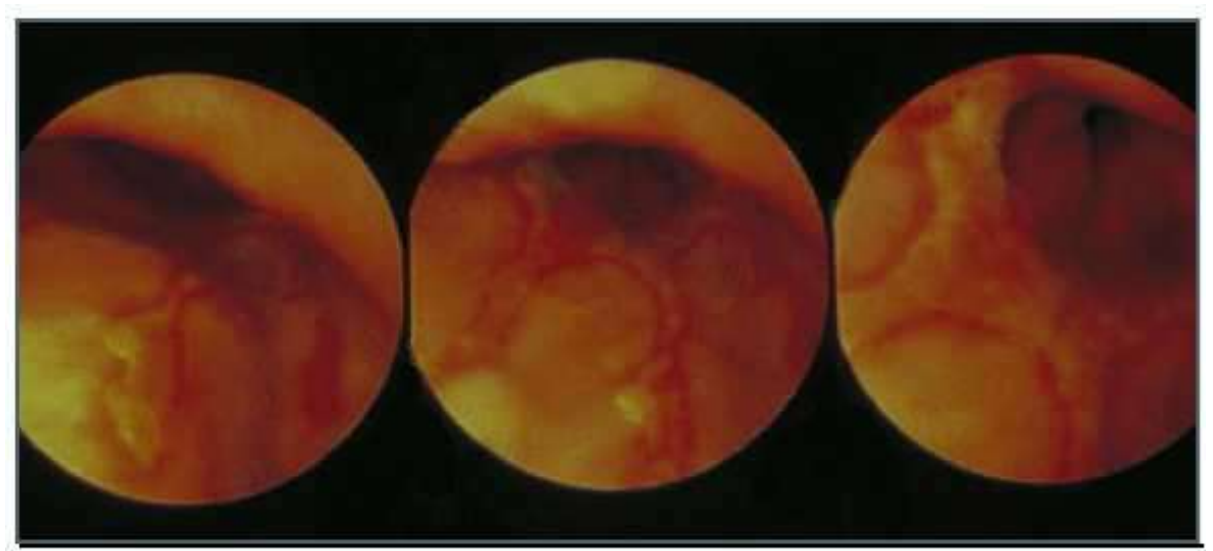

Figure No.1 Esophagitis 


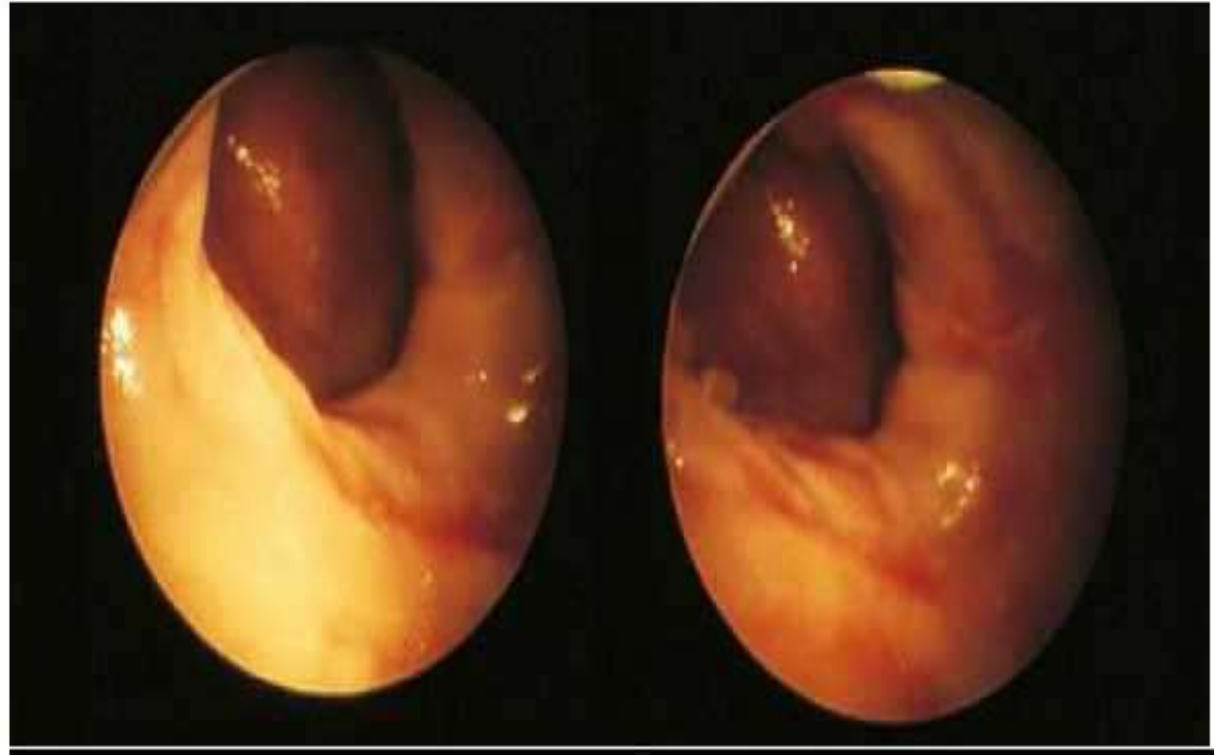

Figure No.2 Sliding Hiatus Hernia

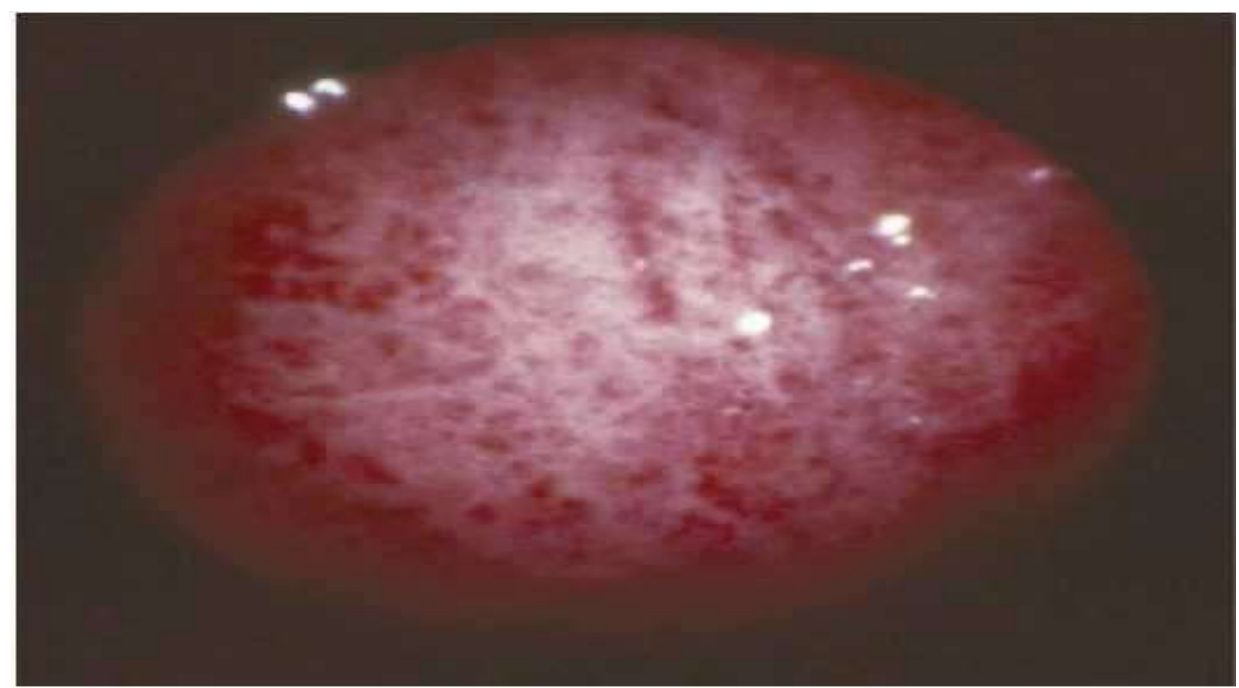

figure no.3 gastritis

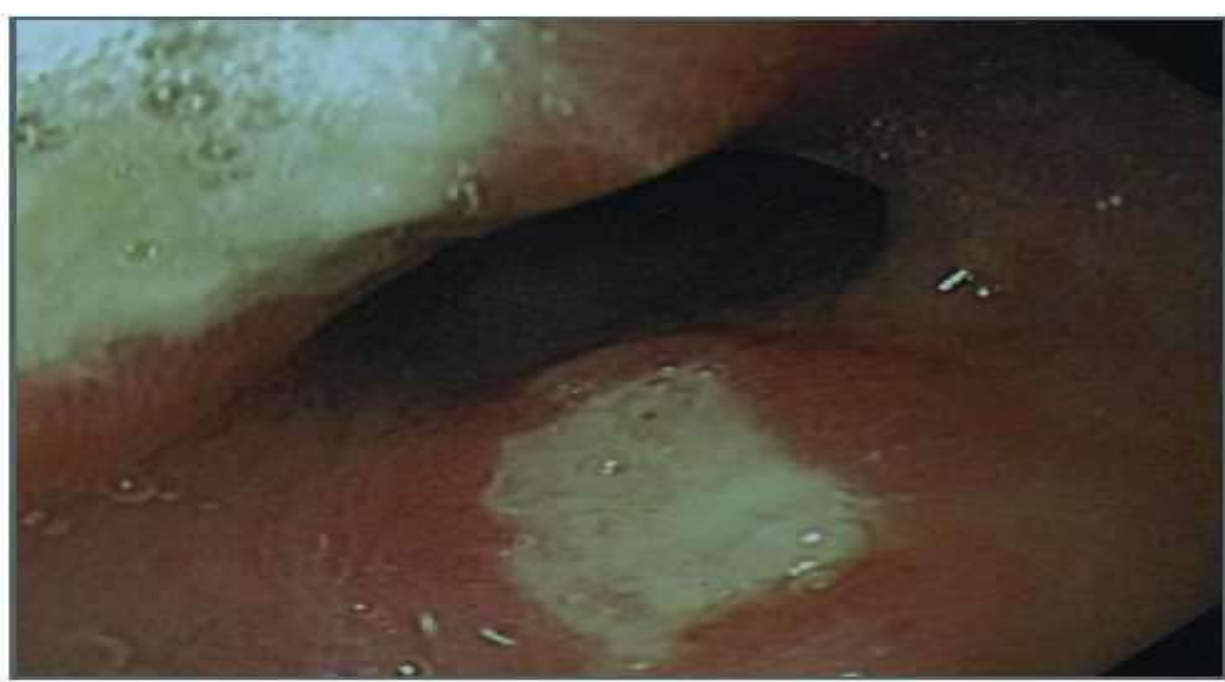

figure no.4 gastric ulcer 


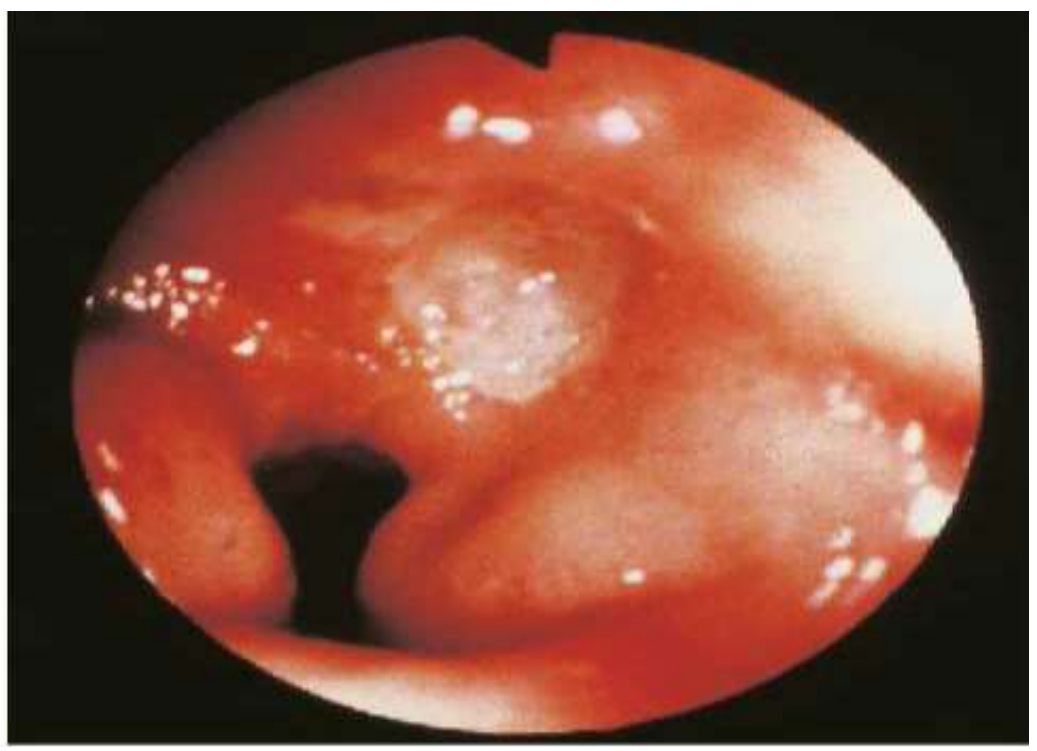

Figure No.5 duodenal ulcer

\section{Discussion}

\begin{tabular}{|l|l|l|l|l|}
\multicolumn{7}{|l|}{ 11.1 Age Distribution } \\
\hline $\begin{array}{l}\text { AGE IN } \\
\text { YEARS }\end{array}$ & $\begin{array}{l}\text { PRESENT } \\
\text { SERIES(\%) }\end{array}$ & $\begin{array}{l}\text { SASODA 17 } \\
\text { SERIES(\%) }\end{array}$ & $\begin{array}{l}\text { AL-OBAIDI 18 } \\
\text { SERIES(\%) }\end{array}$ & $\begin{array}{l}\text { GAHARWAR } \\
19 \\
\text { SERIES(\%) }\end{array}$ \\
\hline$<30$ & 10 & 8 & 5.88 & 15.16 \\
\hline $30-60$ & 82.5 & 60 & 64.71 & 81.81 \\
\hline$>60$ & 7.5 & 32 & 29.41 & 3.03 \\
\hline
\end{tabular}

Table No.8

In the present study, the most common age group presenting with cholelithiasis and dyspepsia was between 30 to 60 years, accounting for $82.5 \%$, followed by less than 30 years age group with $10 \%$. Similar findings were found in Gaharwar series with 30-60 years age group accounting for $81.81 \%$, age group of less than 60 years accounting for $10 \%$ and age group of more than 60 years accounting for $7.5 \%$.

Findings in Sasoda series were as follows: age group between 30-60 years accounted for 60\%, age more than 60 years accounted for $32 \%$ and less than 30 accounted for $8 \%$.

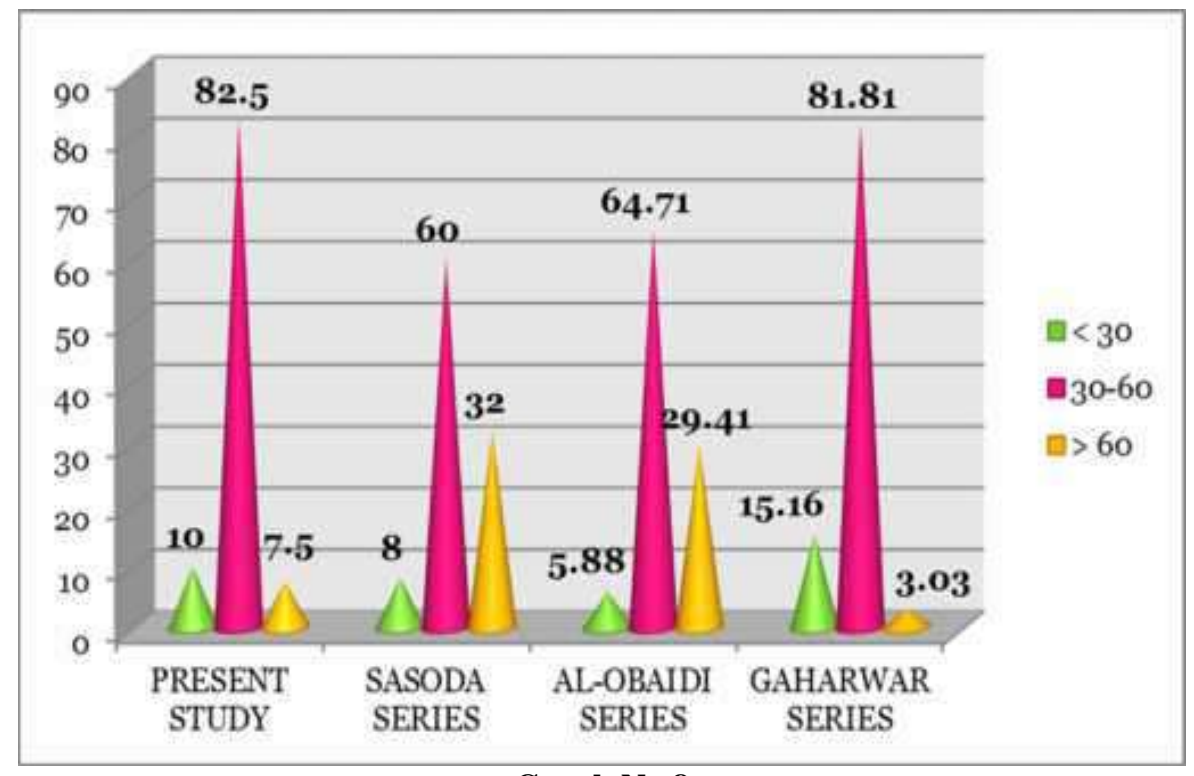

Graph No.8 
In Al-Obaidi series, the age group between 30-60 years accounted for $64.71 \%$, more than 60 years for $29.71 \%$ and less than 30 accounted for $5.88 \%$. Since both gallstones and dyspepsia are common in middle-ages, this finding is consistent with the general population.

11.2 Sex Distribution

\begin{tabular}{|l|l|l|l|l|}
\hline SEX & $\begin{array}{l}\text { PRESENT } \\
\text { SERIES(\%) }\end{array}$ & $\begin{array}{l}\text { MOZAFAR20 } \\
\text { SERIES(\%) }\end{array}$ & $\begin{array}{l}\text { URE 21 } \\
\text { SERIES(\%) }\end{array}$ & $\begin{array}{l}\text { GAHARWAR } \\
\text { 19SERIES }(\%)\end{array}$ \\
\hline MALE & 32.5 & 25.87 & 25 & 91.66 \\
\hline FEMALE & 67.5 & 74.15 & 75 & 8.33 \\
\hline
\end{tabular}

Table No.9

In the present study, cholelithiasis with dyspepsia was more common in female, constituting for $67.5 \%$ of the study group.similar findings were noted in Mozafar series and Ure series where females accounted for $74.15 \%$ and $75 \%$ respectively.

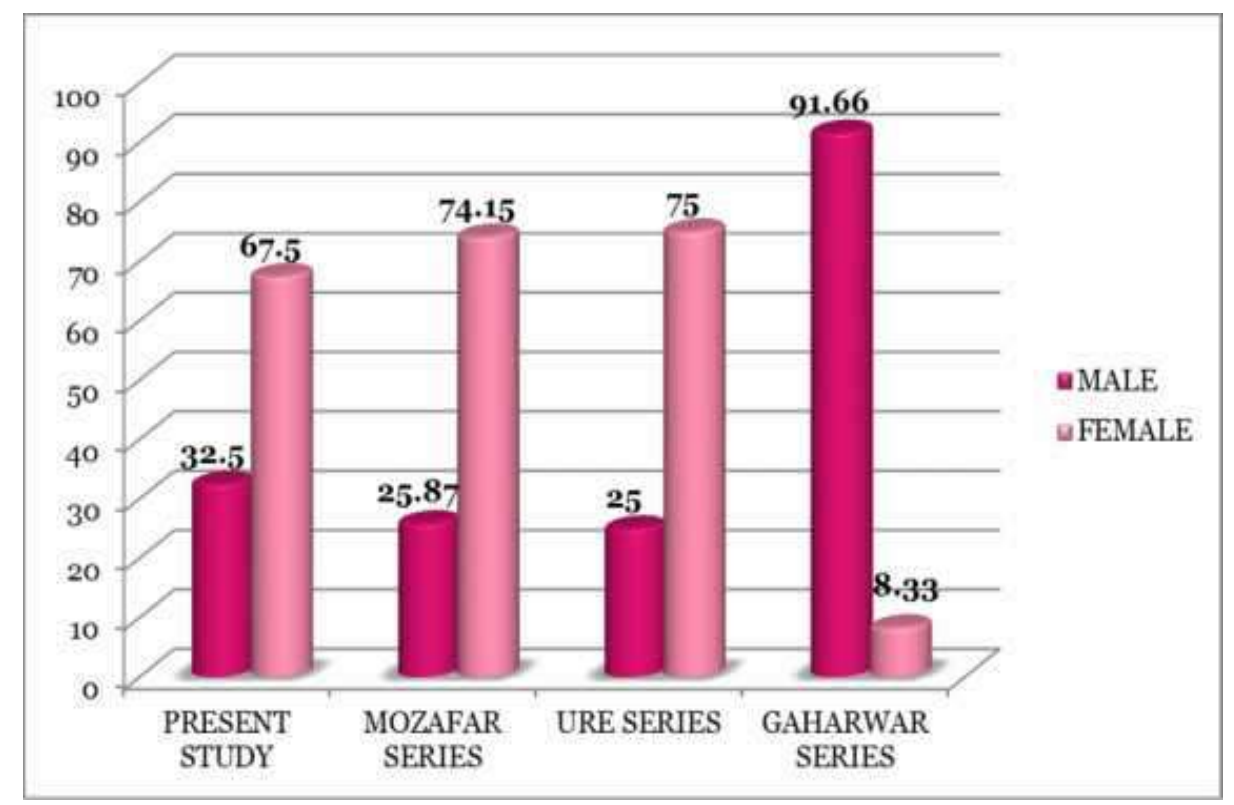

Graph no.9

In the present study, male constituted for $32.5 \%$ of the study group. In Mozafar series and Ure series male accounted for $25.87 \%$ and $25 \%$ respectively.

In Gaharwar series, female accounted for only $8.33 \%$ and male accounted for $91.66 \%$. The prevalence is more common in female in all the studies except for Gaharwar series.

11.3 Dyspeptic Symptoms

\begin{tabular}{|l|l|l|l|l|}
\hline SYMPTOMS & $\begin{array}{l}\text { PRESENT } \\
\text { SERIES(\%) }\end{array}$ & $\begin{array}{l}\text { BERGER22 } \\
\text { SERIES(\%) }\end{array}$ & $\begin{array}{l}\text { URE 21 } \\
\text { SERIES(\%) }\end{array}$ & $\begin{array}{l}\text { RASHID23 } \\
\text { SERIES(\%) }\end{array}$ \\
\hline PAIN ABDOMEN & 70 & 89.04 & 82.9 & 75 \\
\hline HEART BURNS & 47.5 & 50.68 & & 13.33 \\
\hline BELCHING & 30 & 77.77 & & \\
\hline $\begin{array}{l}\text { POST PRANDIAL } \\
\text { FULLNESS }\end{array}$ & 47.5 & 63.01 & 71.2 & 16.67 \\
\hline NAUSEA & 35 & 59.5 & 59.5 & \\
\hline VOMITING & 17.5 & 54.92 & 35.8 & 5 \\
\hline
\end{tabular}

In the present study, pain abdomen was the most common dyspeptic symptom accounting for $70 \%$ followed by heartburn and post prandial fullness accounting for $47.5 \%$. Other symptoms include nausea (35\%), belching (30\%) and vomiting (17.5\%) 


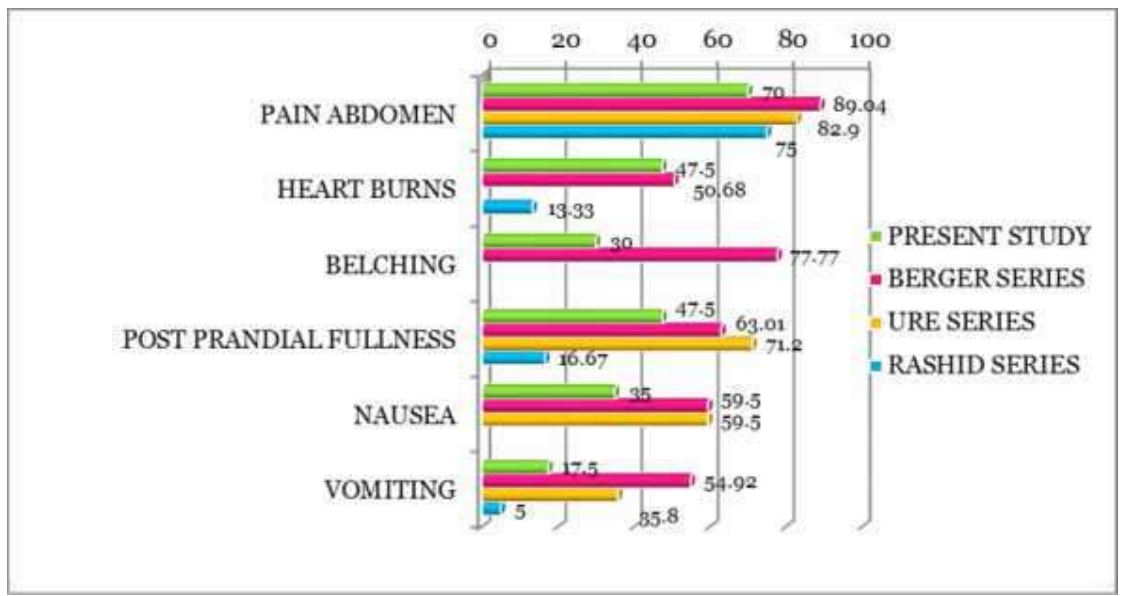

Graph No.10

In Rashid series, pain abdomen was the most common symptom accounting for $75 \%$ in congruence with the present study. But heart burn and post prandial fullness constituted only for $13.3 \%$ and $16.6 \%$ respectively. In Ure series and Berger series, pain abdomen was the most common symptom accounting for $82.9 \%$ and $89.04 \%$ respectively. All the studies show that pain abdomen is the most common presenting symptom. Post prandial fullness and belching are part of the same spectrum of presentation, i.e flatulence.

\subsection{Incidence Of Positive Egd Findings}

\begin{tabular}{|l|l|l|l|l|}
\hline EGD Findings & $\begin{array}{l}\text { Present } \\
\text { Series(\%) }\end{array}$ & $\begin{array}{l}\text { Schwenk24 } \\
\text { Series(\%) }\end{array}$ & $\begin{array}{l}\text { Diettrich 25 } \\
\text { Series(\%) }\end{array}$ & $\begin{array}{l}\text { Thybusch26 } \\
\text { Series(\%) }\end{array}$ \\
\hline $\begin{array}{l}\text { Positive } \\
\text { Findings }\end{array}$ & 77.5 & 30.2 & 31 & 47.3 \\
\hline $\begin{array}{l}\text { Negative } \\
\text { Findings }\end{array}$ & 22.5 & 69.8 & 69 & 52.7 \\
\hline
\end{tabular}

Table no. 11

On subjecting the patients of gallstone disease with atypical symptoms to EGD,abnormal upper gastrointestinal findings were found in $77.5 \%$ of patients in the present study. In Thybusch series, the incidence of positive EGD findings was $47.3 \%$, in Schwenk series it was $30.2 \%$ and $31 \%$ in Diettrich series.

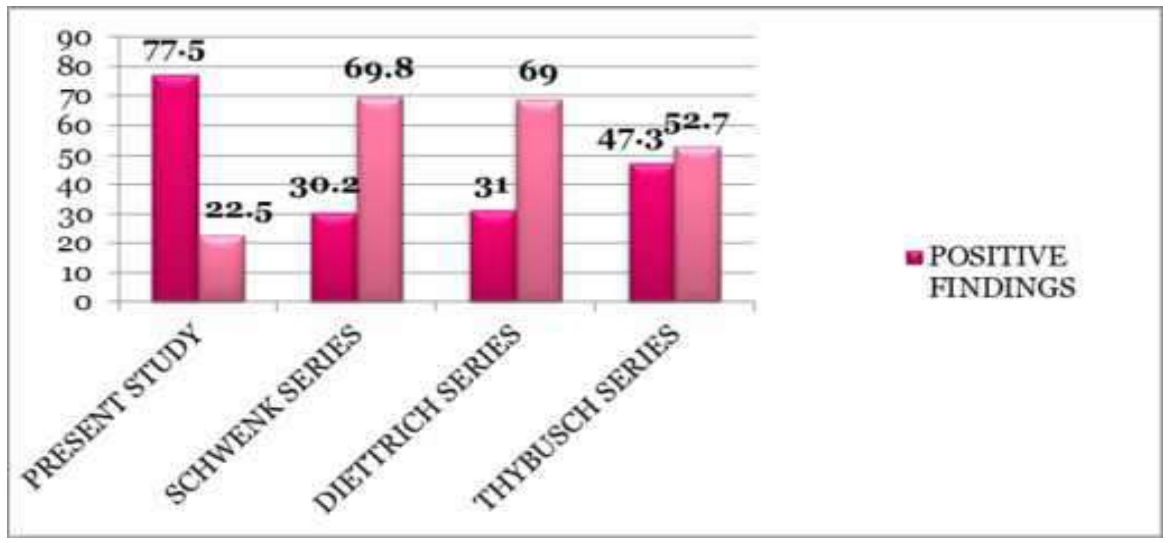

Graph no.11

The higher incidence of positive findings in the present study might be attributed to higher incidence of consumption of spicy food and tobacco in the study population.

\subsection{Egd Findings}

In the present series, $22.5 \%$ of the study group had normal study. In patients having clinically significant EGD findings Gastritis/gastric ulcer (42.5\%) accounted for the most common finding followed by hiatal hernia (27.5\%), esophagitis (17.5\%) duodenitis and duodenal ulcer 10\% each. In Ibrahim series, $43.5 \%$ of the study group had normal study. Gastritis/gastric ulcer was the most common significant finding accounting for $35.5 \%$ followed by esophagitis (19\%). In Bartoz series, $29.7 \%$ of the study population had normal EGD 
study. Gastritis/gastric ulcer was the most common significant finding accounting for $43.6 \%$, followed by duodenitis $(17.3 \%)$, hiatal hernia $(16.10 \%)$, duodenal ulcer $(8.3 \%)$. The percentage of normal EGD was lower in the present study compared to other series. This could be due to high incidence of tobacco/guthka chewing and spicy food intake in our study group. All the studies show that gastritis is the most common EGD finding.

\begin{tabular}{|l|l|l|l|}
\hline Egd Findings & $\begin{array}{l}\text { Present } \\
\text { Series(\%) }\end{array}$ & $\begin{array}{l}\text { Ibrahim 27 } \\
\text { Series(\%) }\end{array}$ & $\begin{array}{l}\text { Bartosz 28 } \\
\text { Series(\%) }\end{array}$ \\
\hline Normal & 22.5 & 43.5 & 29.7 \\
\hline Esophagitis & 17.5 & 19 & 8 \\
\hline Hiatal Hernia & 27.5 & 9.5 & 16.1 \\
\hline $\begin{array}{l}\text { Gastritis/Gastric } \\
\text { Ulcer }\end{array}$ & 42.5 & 35.5 & 43.6 \\
\hline Duodenitis & 10 & 6.5 & 17.3 \\
\hline Duodenal Ulcer & 10 & 3.5 & 8.3 \\
\hline Others & & 10 & \\
\hline
\end{tabular}

Table no.12

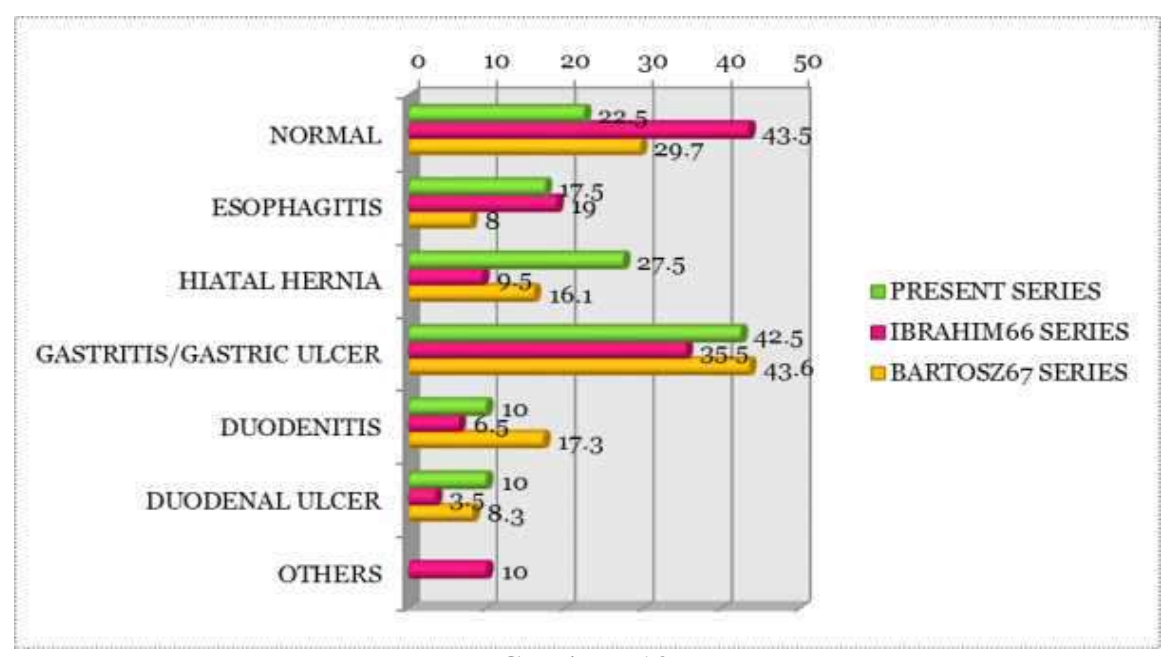

Graph no.12

Many studies have emphasized on the potential therapeutic role of upper gastrointestinal tract endoscopy in the presence of overlapping upper GI symptoms. For instance, Rassek et al. suggests that endoscopic examination of the upper gastrointestinal tract is highly recommended prior to an elective cholecystectomy. In his study, 589 of 960 patients underwent endoscopy ahead of elective cholecystectomy. Although, 56\% had normal endoscopy, $11.3 \%$ underwent a change in plan of management because of the EGD findings and 11 patients were discharged after conservative medical therapy $(1.1 \%) .{ }^{1}$ Endoscopy of GI Tract In another prospective study, the routine EGD of the upper gastrointestinal tract was carried out in 100 patients before they underwent elective cholecystectomy for gallstones, Diettrich et al. found that 31/100 patients had abnormal EGD which changed their subsequent plan of treatment. In $18 \%$ of patients, the cholecystectomy was deferred for 4 to 8 weeks, after additional medical treatment and 7 patients were discharged on only conservative medical treatment. Therefore, he recommended that preoperative endoscopy of the upper gastrointestinal tract should be used in patients undergoing cholecystectomy to rule out other gastrointestinal disorders. $^{2}$

Likewise, another study by Schwenk et al, ${ }^{3} 1143$ patients underwent preoperative EGD or upper gastrointestinal series prior to cholecystectomy. The incidence of pathological findings was $30.2 \%$ (345 patients), with $68.3 \%$ of findings were of inflammatory in nature. In 28 patients $(2.5 \%)$ cholecystectomy or bile duct exploration was combined with an additional gastrointestinal surgical procedure. In 227 cases (19.8\%) biliary surgery was followed by medical treatment of coexisting gastrointestinal diseases. Because of the high incidence of simultaneous Upper GI diseases, they recommended that routine preoperative endoscopy is indicated before elective surgical treatment of gallstones disease. Yavorski et al, ${ }^{4}$ recommend that patients who present with cholelithiasis and atypical abdominal pain undergo preoperative EGD, as they found that at least 9 per cent of the patients in their study had significant findings that altered their management. On the other hand, Sosada et al. recommended the performance of routine EGD for each patient who is elected to undergo laparoscopic cholecystectomy. ${ }^{5}$ He suggested that in patients with asymptomatic gallstones, abdominal pain is most likely secondary to underlying peptic ulcer disease. In this study, EGD which was performed 1-4 days 
prior to surgery in 2800 patients. Pathological findings were identified in 1187(42\%) patients; gastric ulcer in $179(6.4 \%)$, duodenal ulcer in $127(4.5 \%)$, gastritis in 375 [(26.3\%), polyps in $143(5.1 \%)$ and cancer in 3 $(0.1 \%)$ patients. The surgery was delayed for patients with ulcers and they were treated appropriately. 16 patients had complete resolution of symptoms after medical treatment, therefore cholecystectomy was not performed.

In the same way, Rashid et al evaluated the routine use of EGD prior to laparoscopic cholecystectomy. ${ }^{6}$ In his retrospective analysis, the routine use of EGD resulted in detection of other coexisting pathologies in about one third (33\%) of patients. All of these EGD findings lead to a change in the management plan for these patients. Also they noticed that, the recurrence or persistence of symptoms was significantly higher in patients who were not scoped prior to surgery (33\%) in comparison to patients who were scoped where only $(3.3 \%)$ had recurrent or persistent symptoms. Therefore they suggested that, EGD should be considered as a routine investigation before laparoscopic cholecystectomy especially in those selected group of patients, who do present with overlapping upper GI symptoms.

The data suggest that routine use of EGD before laparoscopic cholecystectomy will help to reduce postoperative persistence of symptoms and may reduce overall cholecystectomy rates with beneficial clinical and economical outcomes.

Although there is growing evidence that preoperative EGD is useful in identifying medically treatable diseases in patients undergoing surgical removal of gallstones, few studies however suggested that EGD prior to surgical removal of gallstones has little or no influence on the postoperative outcome ${ }^{7,8}$ For instance, Ure et $a l^{9}{ }^{9}$ suggested that routine endoscopy before laparoscopic cholecystectomy is neither clinically useful nor cost effective in patients with symptomatic gallstone disease. Nevertheless this suggestion was related exclusively to patients with typical gallstone symptoms. Besides, even in patients with typical biliary symptoms EGD abnormalities were found in 60 patients $(16.0 \%)$; these included peptic ulcer, gastric erosions and oesophagitis Thirty patients were treated medically and two by endoscopic polypectomy. In four patients endoscopy led to cancellation of cholecystectomy . Similarly, the significance of preoperative EGD in patients scheduled for laparoscopic cholecystectomy was also evaluated by Al-Azawi et al. ${ }^{8}$ They compared a group of patients who underwent EGD before laparoscopic cholecystectomy and a group of patients who underwent laparoscopic cholecystectomy with no preoperative EGD. In this study, 218[(54.5\%) of 400 patients underwent EGD prior to cholecystectomy. In the EGD group, there were normal findings in $98(45 \%)$ patients. Disorders such as hiatus hernia $(21 \%)$, acute duodenal ulcers $(3.6 \%)$, esophagitis $(3.6 \%)$, gastric ulcer $(0.4 \%)$, and Barrett's oesophagus $(0.4 \%)$ were among the findings. Laparoscopic cholecystectomy was avoided in six patients with chronic cholecystitis. However, in this study, the use of preoperative EGD had no apparent benefit in reducing the incidence of postoperative residual abdominal pain. Therefore they suggest that EGD prior to laparoscopic cholecystectomy does not have an impact on postoperative residual abdominal pain. Despite that, they have also concluded that EGD can disclose other gastrooesophageal disorders with similar symptoms to gallstones and may change the course of the planned surgery in chronic cholecystitis. A wide variety of symptoms exhibited by patients with gallstones are sometimes not relieved by the removal of gallbladder. The symptoms of gallstones can be variable ranging from nonspecific to acute medical emergency. Eighty percent of patients with cholelithiasis are asymptomatic. Most studies shows generally, patients appear to be symptomatic at the rate of two and three percent. Among them two percent has an overall risk of biliary complications such as acute pancreatitis and acute choledocholithiasis and $0.02 \%$ have the risk of incidence of gallbladder cancer. Among symptomatic patients, half of the patients develop biliary colic within a year.

Though biliary colic is specific for gallstones, most of the patients, however, present with other abdominal symptoms. Unfortunately, till date there is no current evidence that justify the correlation of any other abdominal symptoms beside biliary colic in the diagnosis of gall stones. When the patient present with nonspecific symptoms, the demonstration of gallstone by ultrasound scanning does not exclude the coexistence of other conditions that might be responsible for non specific symptoms as proven by various studies.

\section{Summary}

Gall stone disease is one of the most prevalent diseases in man with age, gender, ethnicity and lifestyle playing important roles in the formation of gall stones. Incidence of asymptomatic gallstones has been understood recently, largely due to application of USG scanning of people for other reasons. Most of the gall stones are silent / asymptomatic with only $1-4 \%$ lifetime risk of becoming symptomatic. Gall stones can have 4 types of clinical presentation. Most commonly they are largely asymptomatic. Gall stones can present with typical biliary colic in about $10-25 \%$ of patients with pain described as severe right upper quadrant or epigastric pain which ebbs and flows, radiating to right shoulder and back. It is usually associated with nausea and vomiting and other dyspeptic symptoms. Gallstone disease can present with atypical symptoms without classical biliary colic. The fourth mode of presentation is in the form of cholecystitis without evidence of gall stones. Dyspepsia (post prandial abdominal fullness, nausea, vomiting ), one of the commonest presenting 
symptoms of gall stone disease, can also be caused by other common conditions of the upper digestive tract GERD, gastritis and hiatal hernia. In the present study, we considered 40 patients with dyspeptic symptoms and radiologically proven cholelithiasis for the study. All patients were subjected to EGD. The most common age group presenting with cholelithiasis and dyspepsia was between 30 to 60 years, accounting for $82.5 \%$, followed by $<30$ years age group with $10 \%$. Cholelithiasis with dyspepsia was more common in females, constituting $67.5 \%$ of the study group. In the present study, pain abdomen was the most common dyspeptic symptom, accounting for $70 \%$, followed by post-prandial fullness and heartburn which accounted for $47.5 \%$. In the present series, $22.5 \%$ of the study group had normal study. In patients having clinically significant endoscopic findings gastritis/gastric ulcer (42.5\%) accounted for the most common finding, followed by hiatal hernia (27.5\%).No endoscopic related complications were seen during the study. Cholelithiasis can present with a complex combination of clinical symptoms which may resemble the presentation of other gastrointestinal diseases. Hence, the use of routine preoperative investigations like upper gastrointestinal endoscopy prior to planning surgical treatment of cholelithiasis may help to identify other potentially treatable medical conditions and hence may reduce overall cholecystectomy rates. Besides its cost effectiveness, it may potentially help in reducing the incidence of postoperative persistence of symptoms.

\section{Conclusion}

In our study, it was found that Dyspepsia with gallstones was commonly seen in females in 30-60 year age group The most common dyspeptic symptom was pain abdomen, followed by heart burn and post prandial fullness. On upper gastrointestinal endoscopy,the most common finding was gastritis/gastric ulcer followed by hiatal hernia, esophagitis and duodenitis in decreasing order. Patients presenting with dyspepsia and gallstones having significant upper GI endoscopic findings should be treated initially by medical management. Routine pre-operative upper GI endoscopy is recommended in all patients with gallstone disease who present with dyspepsia to avoid unnecessary cholecytectomy.

\section{References}

[1]. Rassek D, Osswald J, Stock W. [Routine gastroscopy before cholecystectomy]. Chir- urg. 1988 May;59[(5)]: 335-7

[2]. Diettrich H, Wündrich B, Kobe E, Noack S, Weber K. Gastroscopy before cholecystectomy. Gastroenterol J. 1990; 50:173-4.

[3]. Schwenk W, Böhm B, Badke A, Zarras K, Stock W. Preoperative esophagogastroduodenoscopy before elective surgical therapy of symptomatic cholelithiasis. Leber Magen Darm 1992; 22:225- 9.

[4]. Yavorski CC, Acosta JA, Ragland JJ. Precholecystectomy esophagogastroduodeno- scopy: is it of value? Am Surg. 1995 Dec;61[(12)]:1032-4.

[5]. Sosada K, Zurawinski W, Piecuch J, Stepien T, Makarska J. Gastroduodenoscopy: A routine examination of 2,800 patients before laparoscopic cholecystectomy. Surg Endosc. 2005; 19:1103-8.

[6]. Rashid F, Rashid N, Waraich N, Ahmed J, Iftikhar SY. Role of routine oesophago-gastroduodenoscopy before cholecystectomy. International Journal of Surgery. 2010; 8:236-8.

[7]. Ure BM, Troidl H, Spangenberger W, Lefering R, Dietrich A, Sommer H. Evaluation of routine upper digestive tract endoscopy before laparoscopic cholecystectomy. Br J Surg. 1992 Nov;79[(11)]:1174-7.

[8]. Al-Azawi D, Rayis A, Hehir DJ. Esophagogastroduodenoscopy prior to laparoscopic cholecystectomy. J LaparoendoscAdvSurg Tech A. 2006 Dec;16[(6)]:593-7.

[9]. Ure BM, Spangenberger W, Lefering R, Dietrich A, Troidl H. Routine gastroscopy before laparoscopic cholecystectomy: evaluation of the technology in 376 patients. Z Gastroenterol 1992;30:529-33 